\title{
Synthesis, Characterization and Swelling Study of Poly(Methacrylic acid-Co-maleic acid) Hydrogels
}

\section{SOUMIA BELKADI ${ }^{1 *}$, HAYET BENDAIKHA ${ }^{1,2}$, FOUAD LEBSIR ${ }^{1}$ and SEGHIER OULD-KADA ${ }^{1}$}

\author{
'Laboratory of Macromolecular Physical Chemistry, Department of Chemistry, University of Oran1 \\ Ahmed Ben Bella, BP 1524 EL-M'Naouer, Oran 31100, Algeria. \\ 'Laboratory of Industrial Safety Engineering and Sustainable Development, Department of Industrial \\ Safety and Environment, University of Oran2, Mohamed Ben Ahmed, Oran 31000, Algeria. \\ ${ }^{*}$ Corresponding author E-mail: sbelkadi3169@ hotmail.com
}

\author{
http://dx.doi.org/10.13005/ojc/340244
}

(Received: January 13, 2018; Accepted: March 20, 2018)

\begin{abstract}
A series of poly (methacrylic acid-Co-maleic acid), P(MAA-MA), hydrogels have been prepared by free radical polymerization in aqueous medium using different amount of maleic acid (MA) (0-5 wt.\%), initiated by potassium persulfate (KPS) in the presence of $\mathrm{N}, \mathrm{N}$ '-methylenebisacrylamide (MBA) as a crosslinking agent. Fourier transform infrared spectroscopy (FTIR), thermogravimetric analysis (TGA) and scanning electron microscope (SEM) techniques were used to characterize the prepared hydrogels. Their swelling behaviours were investigated according to the maleic acid content and $\mathrm{pH}$ of solution. Kinetic swelling of hydrogels was studied too. The results showed that the swelling ratios increase with increasing the maleic acid content. Kinetic studies showed good fitting to pseudo-second order equation. The prepared hydrogels obeyed non-Fickian water diffusion.
\end{abstract}

Keywords: Methacrylic acid, Maleic acid, Hydrogels, Swelling, Kinetic order, Diffusion.

\section{INTRODUCTION}

Hydrophilic hydrogels are chemical or physical crosslinked three dimensional macro molecular matrix. Due to their hydrophilic functional groups $\left(-\mathrm{OH},-\mathrm{COOH},-\mathrm{NH}_{2},-\mathrm{CONH}_{2},-\mathrm{SCO}_{3} \mathrm{H}\right)$, they are able to absorb a substantial quantity of water in the swollen state ${ }^{1}$. They are classified as chemical or permanent hydrogels when the networks are crosslinked together through covalent bonding ${ }^{2}$. however, they are called physical or reversible gels when the polymeric chains are linked together by hydrogen bonds, electrostatic and Van der Waals forces ${ }^{2,3}$. 
Known as intelligent, stimuli-responsive or environmentally-sensitive hydrogels, they can respond to a variety of changes in environmental conditions such as temperature, ionic strength, $\mathrm{pH}$ as well as electric field, etc. ${ }^{4}$. These materials are of great interest since they find several applications as separation membranes ${ }^{5}$, sensors ${ }^{6}$, adsorbents, medical and pharmaceutical drug delivery systems, as well as in other various nanotechnology fields ${ }^{7-9}$.

Recently, an enormous number of authors have reported studies on methacrylic acid based hydrogels as multi-target carriers (drugs, metals, dyes). For instance, poly(methacrylicacid)/tannic acid $^{7}$ and $\mathrm{N}$-succinyl chitosan-poly(methacrylic acid $)^{10}$ have been tested for drug release; poly(methacrylic acid)-g-cellulose/bentonite ${ }^{11}$ and poly $(\mathrm{N} \text {-vinylpyrrolidone-methacrylic acid })^{12}$ hydrogels are used as cationic dye uptake. Whereas hydrogels of (chitosan, itaconic and methacrylic acid $)^{13}$ for heavy metal adsorption. However, new adsorbents which have high adsorption capacity are still needed ${ }^{14,15}$. To our knowledge, hydrogels of poly(methacrylic acid-co-maleic acid) were not previously employed to obtain a material for specific application.

In this work, we aim to prepare, by free radical copolymerization, new hydrogels with a high capacity of water uptake using methacrylic acid (MAA) and maleic acid (MA) as co-monomers with different weight ratios, initiated by KPS in the presence of MBA as a crosslinking agent. Hydrogels characterizations were performed by FTIR spectroscopy, ATG and SEM techniques. Swelling behaviour, kinetics as well as $\mathrm{pH}$ responsive properties were also studied. The potential use of these hydrogels as sorbent materials will be investigated in another study.

\section{MATERIALS AND METHODS}

The methacrylic acid (MAA) monomer and crosslinking agent, N,N'-methylenebisacrylamide (MBA) obtained from Fluka A.G, the maleic acid (MA) co-monomer from Prolab, and initiator, potassium persulfate (KPS) from Merck \& Co. were used as received. Distilled water was used in swelling and solution preparations. Buffers solutions with different $\mathrm{pH}$, obtained from dilution of standard aqueous $\mathrm{HCl}$ and $\mathrm{NaOH}$, were used in swelling studies. FTIR analyses of the hydrogels were performed at room temperature on a model Alpha Bruker spectrometer from 4000 to $400 \mathrm{~cm}^{-1}$. A themogravimetric analysis (TGA) of hydrogels was carried out on LABSYS evo under nitrogen atmosphere from 25 to $700{ }^{\circ} \mathrm{C}$ at a heating rate of $10{ }^{\circ} \mathrm{C} /$ minute. The SEM micrographs of the samples were obtained by means of Hirox SH-4000 M model microscope.

\section{Synthesis of hydrogels}

The P(MAA-MA) hydrogels were obtained by free radical copolymerization reaction as shown in scheme 1. First, MAA and MA monomer in various ratios were dissolved in distilled water to obtain $2 \mathrm{~g}$ of total weight. The MA weight fractions were varied from 0 to $5 \mathrm{wt} . \%$. The polymerization reaction was carried out using $\mathrm{K}_{2} \mathrm{~S}_{2} \mathrm{O}_{8}$ (1 wt.\%) as initiator and MBA (1 wt.\%) as crosslinking agent with the respect of the total weight of monomers. The mixture was bubbled with nitrogen gas for $10 \mathrm{~min}$ to remove any oxygen molecules, which could inhibit the polymerization reaction. The copolymerization was conducted at $60{ }^{\circ} \mathrm{C}$ for 6 hours. The experimental reaction conditions are summarized in Table 1. The resulting hydrogels were soaked in water for several days to remove unreacted monomers. Afterwards, they were dried under vacuum at $40^{\circ} \mathrm{C}$ till samples achieved a constant weight.

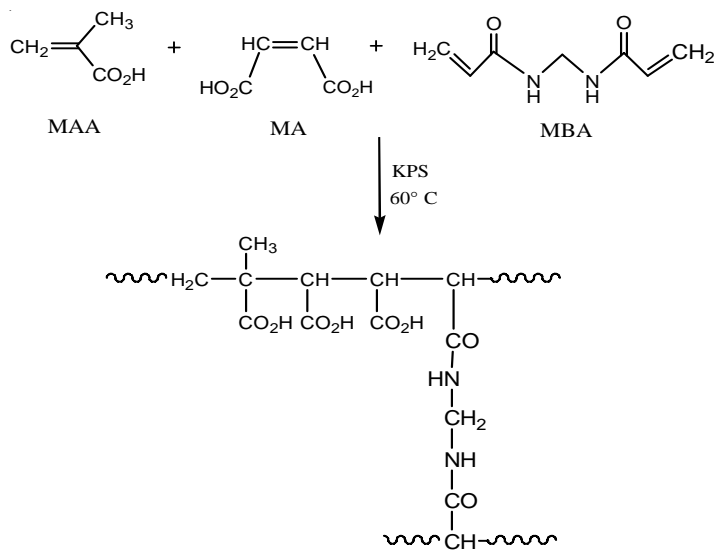

Scheme 1. Synthesis of poly (MAA-MA) hydrogels 
Table 1: Feed compositions of P(MAA-MA) hydrogels

\begin{tabular}{lccccc}
\hline Hydrogels & MAA (wt.\%) & MA (wt.\%) & $\mathrm{K}_{2} \mathrm{~S}_{2} \mathrm{O}_{8}(\mathrm{wt} . \%)$ & MBA (wt.\%) & Water (mL) \\
\hline PMAA & 100 & 0 & 1 & 1 & 10 \\
P(MAA-MA1) & 99 & 1 & 1 & 1 & 10 \\
P(MAA-MA3) & 97 & 3 & 1 & 1 & 10 \\
P(MAA-MA5) & 95 & 5 & 1 & 1 & 10 \\
\hline
\end{tabular}

\section{$\mathrm{pH}$ dependent swelling behaviour}

In order to study the swelling behaviour, gravimetric method was used for the measurement of the swelling degree by immersing dried hydrogels $(0.05 \mathrm{~g})$ in different $\mathrm{pH}$ solutions $(3,4,5.5,6,6.7,7.2,8$ and 10$)$ for $48 \mathrm{~h}$ at room temperature. The swollen hydrogels were removed from the solution at different intervals of time, wiped carefully with a filter paper, weighed and let in the solution until an equilibrium swelling is reached. The swelling degree $\left(S D_{t}\right)$ and equilibrium swelling degree $\left(S_{\mathrm{e}}\right)$ are calculated by the following equations ${ }^{16,17}$.

$$
\begin{aligned}
& \operatorname{SD}_{t}(\%)=\left[\left(W_{t}-W_{d}\right) / W_{d}\right] \times 100 \\
& \operatorname{SD}_{e}(\%)=\left[\left(W_{e}-W_{d}\right) / W_{d}\right] \times 100
\end{aligned}
$$

Where $W_{d}$ and $W_{t}$ are the sample weights of dried and the swollen state (in grams) respectively. $\mathrm{W}_{\mathrm{e}}$ indicates the sample weight at swelling equilibrium (in grams).

\section{Swelling kinetics}

The swelling measurements of the hydrogels were taken at different time intervals then fitted to pseudo-second order equation expressed as follows ${ }^{10}$.

$$
t / m_{t}=1 /\left(k_{2} m_{e q}^{2}\right)+t / m_{\text {eq }}
$$

Where $m_{t}$ and $m_{e q}$ are the swollen hydrogel weights at time $t$ and at equilibrium, respectively. $k_{2}$ denotes a rate constant. Variation of $t / m_{t} v s$. time is plotted in Figure 6.

\section{RESULTS AND DISCUSSIONS}

\section{FTIR spectra}

FTIR spectroscopy is used to study the hydrogel structure. Fig. 1 shows the results from FTIR analyses for PMAA and P(MAA-MA5) samples. The broad absorption band was observed between
3600 and $3100 \mathrm{~cm}^{-1}$ characterizing the $-\mathrm{OH}$ stretching vibrations of $-\mathrm{COOH}$ group of MAA and $M A$ in the hydrogels. It can be noticed that the $-\mathrm{OH}$ peaks in the P(MAA-MA5) is very intense compared to that of PMAA hydrogel. This may be due to the presence of a large amount of $-\mathrm{COOH}$ groups in the P(MAA-MA5), i.e., the intensity of $-\mathrm{OH}$ bands increased as the MA content incorporated in hydrogel increases.The peaks at 2996, 2937 and $2587 \mathrm{~cm}^{-1}$ correspond to the $\mathrm{C}-\mathrm{H}$ stretching vibrations. The absorption bands at 1705 and $1690 \mathrm{~cm}^{-1}$ are assigned to the carbonyl groups $(\mathrm{C}=\mathrm{O})$ in $\mathrm{P}$ (MAA-MA5) and PMAA respectively. The $\mathrm{C}-\mathrm{O}$ band is observed at 1253 and $1166 \mathrm{~cm}^{-1} 5,18$. The absorption band detected at $1483 \mathrm{~cm}^{-1}$ is attributed to $\mathrm{C}-\mathrm{N}$ bond in the MBA molecule ${ }^{19}$.

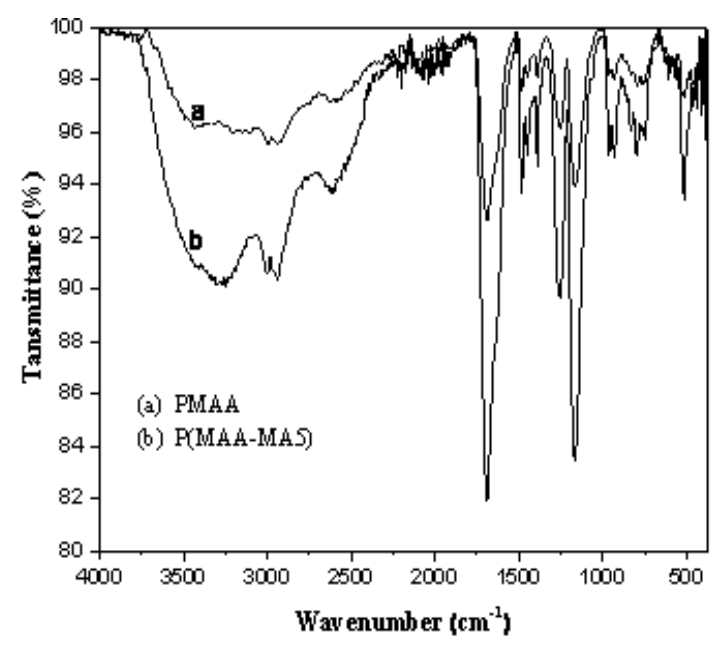

Fig. 1. FTIR spectra: a) PMAA b) P(MAA-MA5) hydrogels

\section{Thermal analysis}

Figure 2 shows the thermal degradation of PMAA and P(MAA-MA5) samples by weight loss as a function of temperature. It was observed that there was no weight loss up to $75^{\circ} \mathrm{C}$ and $150^{\circ} \mathrm{C}$ for both PMAA and P(MAA-MA5), respectively which can be related to water molecules loss ${ }^{20,21}$. PMAA 
and $\mathrm{P}$ (MAA-MA5) hydrogels present sharp weight loss at $260{ }^{\circ} \mathrm{C}$ and $395{ }^{\circ} \mathrm{C}$ respectively, indicating the decomposition of the hydrogels backbone. The copolymer MAA/MA with 5 wt. $\%$ of MA content showed an increase in thermal stability over PMAA hydrogel (P(MAA-MA5) decomposes at a higher temperature than PMAA).

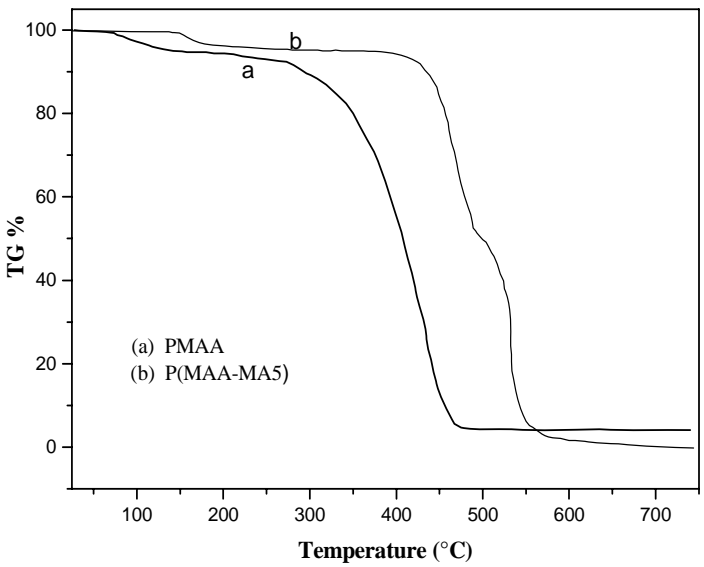

Fig. 2. TGA thermograms curves: a)

PMAA b) P(MAA-MA5) hydrogels

Scanning electron microscope

The morphological analysis was performed using scanning electron microscopy. The results obtained from SEM micrographs of PMAA and $\mathrm{P}(\mathrm{MAA}-\mathrm{MA5}$ ) hydrogels are shown in Fig. $3 \mathrm{a}$ and $3 b$. It revealed that PMAA hydrogel had a rigid heterogeneous structure. On the other hand, P(MAA-MA5) showed different structure comparing with PMAA one with small voids dispersed over the entire surface. This is may be due to the high hydrophilicity of hydrogel.
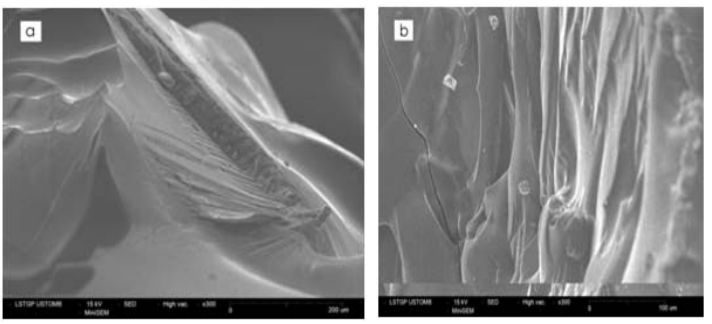

Fig. 3. SEM of a) PMAA and b) P(MAA-MA5) hydrogels (magnification $\times 300$ )

\section{Swelling behaviour study}

In the present work, swelling measurements were conducted, as a function of time, for hydrogels prepared at different monomer concentrations. The swelling behaviour of hydrogels is represented in Fig. 4. It was noticed that P(MAA-MA) hydrogels showed high degree of swelling compared to that of pure PMAA. The results revealed that the swelling degree at equilibrium ( $S D_{e}$ ) increased with increasing MA content (0-5 wt.\%) in the hydrogels. The value of $\mathrm{SD}_{e}$ increased from $3200 \%$ for PMAA to $4700 \%$ for P(MAA-MA5). Yang M. et al., (2010) and Bennour S. et al., (2014) have reported that the swelling is induced by ionic charge repulsion within the polymeric chains of the hydroge ${ }^{22,23}$. Due to the increase of MA content, the $-\mathrm{COOH}$ groups increased, thereby increasing the electrostatic repulsion among $\mathrm{COO}^{-}$groups and thus leading to the expansion of the polymeric chains of the hydrogel.

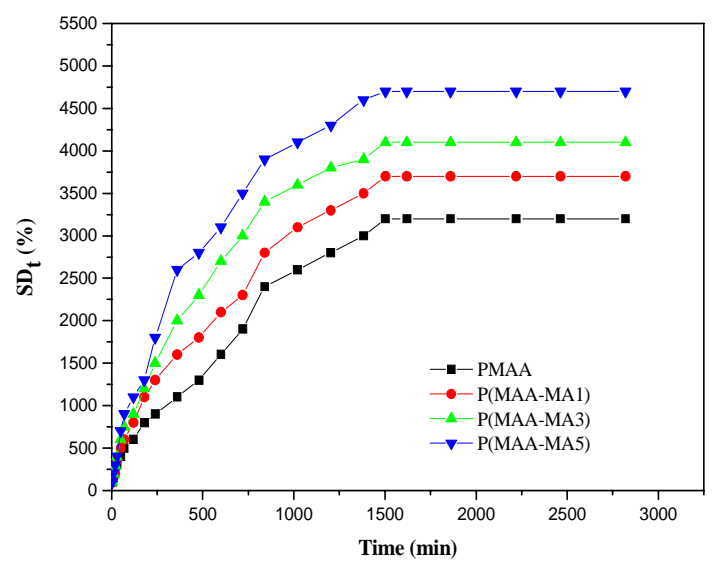

Fig. 4. Effect of MA content on swelling ratio of PMAA and P(MAA-MA) hydrogels (pH 6.7 at room temperature)

\section{Influence of $\mathrm{pH}$ on the swelling}

In order to investigate the effect of $\mathrm{pH}$ on swelling behaviour, the hydrogel samples were soaked in different $\mathrm{pH}$ solutions $(3,4,5.5,6,6.7$, $7.2,8$, and 10) at room temperature. Fig. 5 illustrates the equilibrium swelling degree versus $\mathrm{pH}$ values for both PMAA and P(MAA-MA) hydrogels. It has been noticed for all hydrogels studied, the highest swelling capacity was reached at $\mathrm{pH}$ of 6.7 . This is due to the complete ionization of carboxylic groups present in MAA and MA around this $\mathrm{pH}$ value ${ }^{24}$. Beyond $\mathrm{pH}$ 6.7, the swelling ratio of hydrogels decreases. Souda P. et al., (2014) had explained that there is a competition between the shielding effect of the carboxylate and the screening effect of the counter ions ${ }^{19}$. At the $\mathrm{pH}$ value of 3 , carboxylic groups display hydrophobic character because of their low ionization; therefore the polymer with more carboxylic groups swells less ${ }^{25}$. 


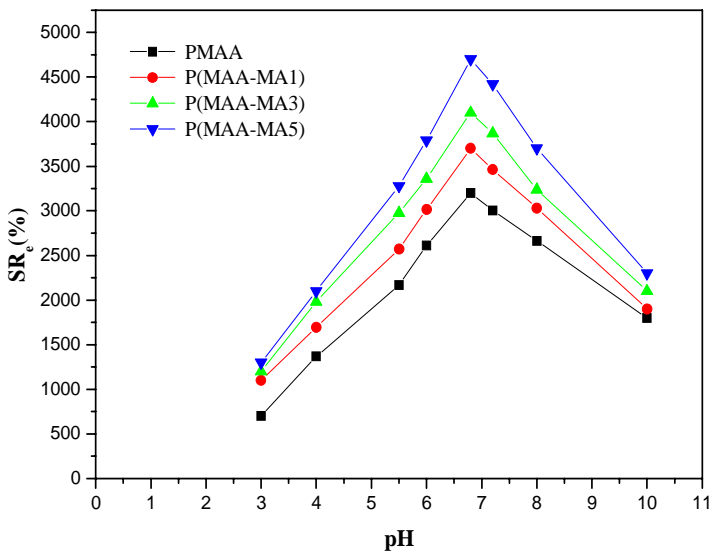

Fig. 5. Equilibrium swelling ratio as a function of $\mathrm{pH}$ values

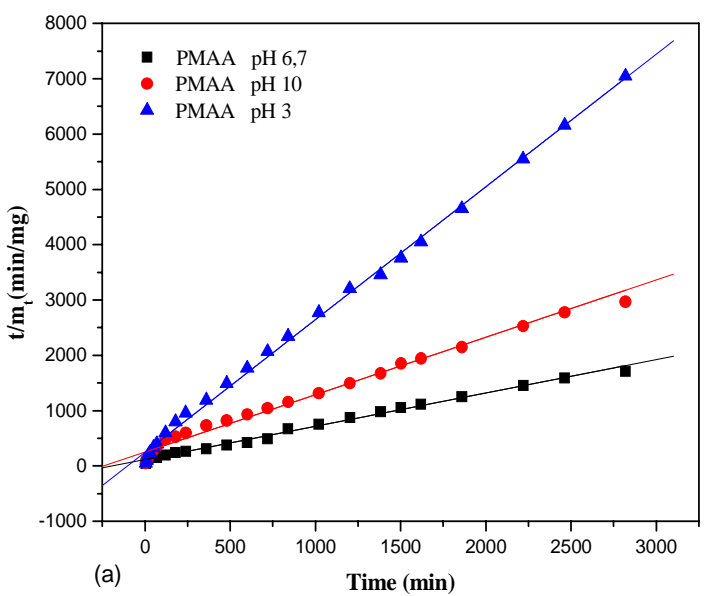

\section{Swelling Kinetic studies}

The experimental swelling ratio results, obtained from pseudo-second order kinetic equation Eq. (3), of PMAA and P(MAA-MA5) hydrogels are summarized in Table 2. The calculated kinetic parameters fitted well to the pseudo second order model according to the value of coefficient of regression $\left(R^{2}\right)$ which is very close to unity. The swelling kinetic curves of hydrogels are given in Fig. $6 a$ and $6 b$.

\section{Diffusion kinetics}

Diffusion mechanism of water molecules within polymeric networks is of great interest in the last few decades due to their enormous important

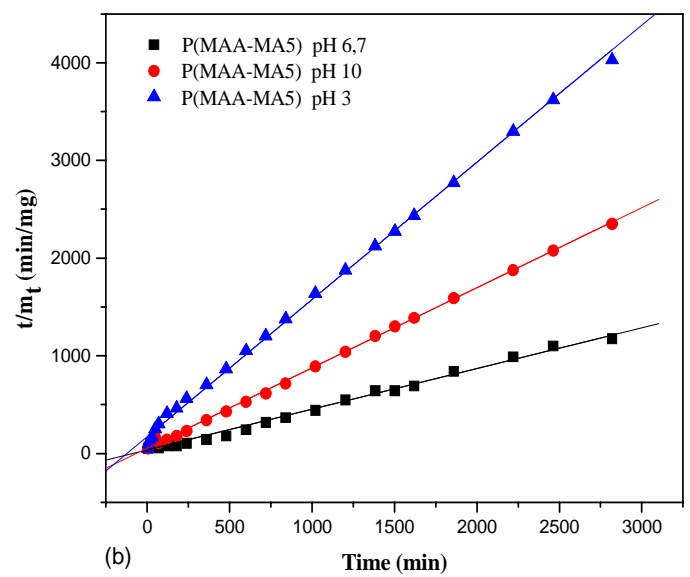

Fig. 6. Swelling kinetic curves: a) PMAA b) P(MAA-MA5) hydrogels at different pH

Table 2: Swelling kinetics parameters of hydrogels in water

\begin{tabular}{lcccccccc}
\hline \multicolumn{3}{c}{ PMAA } \\
\hline $\mathrm{pH}$ & $\begin{array}{c}\mathrm{m}_{\text {exp. }} \\
(\mathrm{g})\end{array}$ & $\begin{array}{c}\mathrm{m}_{\text {cal. }}(\mathrm{g}) \\
\end{array}$ & $\begin{array}{c}\mathrm{K}_{2} \cdot 10^{3} \\
(\mathrm{~g} / \mathrm{min} .)\end{array}$ & $\mathrm{R}^{2}$ & $\begin{array}{c}\mathrm{m}_{\text {exp. }} \\
(\mathrm{g})\end{array}$ & $\begin{array}{c}\mathrm{m}_{\text {cal. }} \\
(\mathrm{g})\end{array}$ & $\begin{array}{c}\mathrm{K}_{2} \cdot 10^{3} \\
(\mathrm{~g} / \mathrm{min} .)\end{array}$ & $\mathrm{R}^{2}$ \\
\hline 3 & 0.40 & 0.416 & 1.023 & 0.997 & 0.7 & 0.712 & 3.055 & 0.995 \\
6.7 & 1.65 & 1.659 & 4.326 & 0.995 & 2.4 & 2.403 & 7.131 & 0.998 \\
10 & 0.95 & 0.963 & 3.164 & 0.997 & 1.2 & 1.217 & 5.280 & 0.998 \\
\hline
\end{tabular}

applications in scientific as well as engineering fields such as medicine, textile industry, membrane separations, packaging in food industry, extraction of solvents and of contaminants, etc. ${ }^{23}$. The diffusion mechanism of water into hydrogels can be determined using the following expression ${ }^{26,27}$.

$F=M_{t} / M_{\infty}=k t^{n}$
Where, $\mathrm{M}_{\mathrm{t}}$ and $\mathrm{M}_{\infty}$ are the amount of water intake into the hydrogel at time $t$ and equilibrium, respectively. $\mathrm{t}$ is the swelling time, $\mathrm{n}$ is the diffusion exponent, describing the transport mechanism (type of water penetration) and $\mathrm{k}$ is a constant related to the three-dimensional structure. When $\mathrm{n}=0.5$, the mechanism is Fickian water diffusion; however, the values of $n$ lying in the range of 
$0.5<\mathrm{n}<1$ indicate an anomalous non-Fickian mechanism diffusion, where both diffusion and polymer relaxation control the water intake. $n=1$ define a case II diffusion mechanism. InF is plotted against Int for all hydrogels as shown in Fig. 7. $n$ and $k$ values were determined from the slopes and intercepts of lines and are given in Table 3. For all compositions, the values of $n$ vary between 0.53 and 0.57 , showing non Fickian water diffusion in the hydrogels.

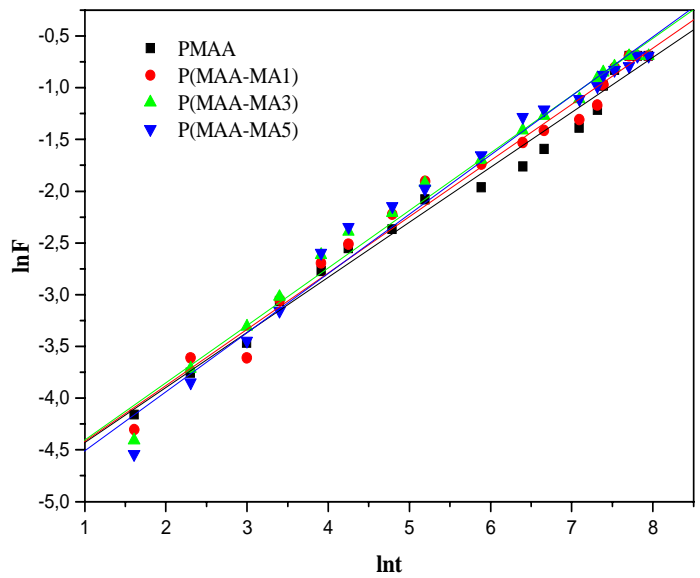

Fig. 7. Plot of InF versus Int of PMAA and P(MAA-MA) hydrogels ( $\mathrm{pH} 6.7$ at room temperature)
Table 3: Diffusion coefficient values for different hydrogels

\begin{tabular}{lccc} 
Hydrogels & $\mathrm{n}$ & Ink & $\mathrm{R}^{2}$ \\
\hline PMAA & 0.53 & -4.958 & 0.993 \\
P(MAA-MA1) & 0.54 & -4.962 & 0.992 \\
P(MAA-MA3) & 0.56 & -4.961 & 0.994 \\
P(MAA-MA5) & 0.57 & -5.082 & 0.990 \\
\hline
\end{tabular}

\section{CONCLUSION}

In this work, intelligent hydrogels based on methacrylic acid and maleic acid prepared by free radical copolymerization have shown very interesting swelling behaviour. For instance, an increase in MA content in copolymers has led to an increase in the equilibrium swelling degree. The hydrogels have apparent $\mathrm{pH}$ sensitive character with maximum rate of absorption water capacity at $\mathrm{pH}$ 6.7. The water diffusion mechanism in these hydrogels has fitted a pseudo second order model thus obeying a non-Fickian anomalous transport mechanism. The discussed $\mathrm{pH}$-responsive hydrogels might find great potential applications in drug delivery systems or wastewater treatments.

\section{REFERENCES}

1. Sahiner, N.; Ozay, O.; Aktas, N. Chemosphere., 2011, 85, 832-838.

2. Hennink, W. E.; Nostrum, C. F. Adv. Drug Deliver. Rev., 2002, 54, 13-36.

3. Lin, Y. H.; Ling, H. F.; Chang, C. K.; Chen, M. C.; Sung, H. W. Biomaterials., 2005, 26, 2105-2113.

4. Panic, V.; Adnadjevic, B.; Velickovic, S.; Jovanovic, J. Chem. Eng. J., 2010, 156, 206-214.

5. Sagle, A. C.; Ju, H.; Freeman, B. D.; Sharma, M. M. Polymer., 2009, 50, 756-766.

6. Buenger, D.; Topuz, F.; Grol, J. Prog. Polym. Sci., 2012, 37, 1678-1719.

7. Sahiner, N.; Sengel, S. B. Colloid. Surface A., 2016, 508, 30-38.

8. Lally, S.; Mackenzie, P.; Lemaitre, C. L.; Freemont, T. J.; Saunders, B. R.J. Colloid Interface Sci., 2007, 316, 367-375.

9. Dadsetan, M.; Taylor, K. E.; Yong, C.; Bajzer,
Z.; Lu, L.; Yaszemski, M. J. Acta. Biomater., 2013, 9, 5438-5446.

10. Bashir, S.; Teo, Y. Y.; Ramesh, S.; Ramesh, K. Polymer., 2016, 92, 36-49.

11. Anirudhan, T. S.; Tharun, A. R. Chem. Eng. J., 2012, 181-182, 761-769.

12. Olpan, D.; KöLge, Z. Radiat. Phys. Chem., 2006, 75, 120-128.

13. Milosavljevic, N. B.; Ristic, M. D.; Peric-Grujic, A. A.; Filipovic, J. M.; Štrbac, S. B.;"Rakocevic, Z. L.; Kalagasidis Krušiè, M. T.Colloid. Surfaces A., 2011, 388, 59-69.

14. Fu, J.; Chen, Y. J.; Ju, J. Y.; Li, Q. S.; An, S. Q.; Zhu, H. L. Pol. J. Environ. Stu., 2011, 20, 61-66.

15. Cai, Z. Q.; Sun, Y.; Liu, W.; Pan, F.; Sun, P.; Fu, J.Environ. Sci. Pollut. Res., 2017, 24, 15882-15904.

16. Kam, E.; Tasdelen, B.; Osmanlioglu, A. E. 
Radiat. Phys. Chem., 2012, 81, 618-621.

17. Hosseinzadeh, H.; Orient. J. Chem., 2013, 29, 161-166.

18. Panic, V. V.; Madzarevic, Z. P.; Volvov-Husovic, T.; Velickovic, S. J. Chem. Eng. J., 2013, 217, 192-204.

19. Souda, P.; Sreejith, L. Polym. Bull., 2014, 71, 839-854.

20. Wei, W.; Qi, X.; Liu, Y.; Li, J.; Hu, X.; Zuo, G.; Zhang, J.; Dong, W. Colloid. Surface B., 2015, 136, 1182-1192.

21. Podkoscielna, B.; Bartnicki, A.; Gawdzik, B. Express Polym. Lett., 2012, 9, 759-771.
22. Yang, M.; Liu, B.; Gao, G.; Liu, X.; Liu, F. Chinese J. Polymer. Sci., 2010, 28, 951-959.

23. Bennour, S.; Louzri, F. Adv. Chem., 2014, article ID 147398, 1-10.

24. Tomic,S. L. J.; Micic, M. M.; Filipovic, J. M.; Suljovrujic, E. H. Radiat. Phys. Chem., 2007, 76, 1390-1394.

25. Kasgoz, H.; Aydin, l.; Kasgoz, A. Polymer. Bull., 2005, 54, 387-397.

26. Çöle, G.; Gök, M. K.; Güçlü, G. Water Air Soil Pollut., 2013, 224, 1760-1776.

27. Peppas, N. A.; Franson, N. M. J. Polym. Sci. Pol. Phys., 1983, 21, 983-997. 